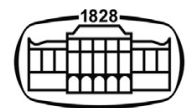

AKADÉMIAI KIADÓ

Journal of Behavioral Addictions

9 (2020) 2, 190-205

DOI:

$10.1556 / 2006.2020 .00024$

(c) 2020 The Author(s)

REVIEW ARTICLE

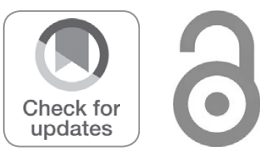

\title{
The Conceptual Framework of Harmful Gambling: A revised framework for understanding gambling harm
}

\author{
MARGO HILBRECHT ${ }^{1,2 *} \odot$, DAVID BAXTER ${ }^{1} \odot$, \\ MAX ABBOTT ${ }^{3}$, PER BINDE ${ }^{4}$, LUKE CLARK ${ }^{5} \odot$, DAVID \\ C. HODGINS ${ }^{6} \odot$, DARREL MANITOWABI ${ }^{7}$, LENA QUILTY ${ }^{8,9}$, \\ JESSIKA SPÅNGBERG ${ }^{10}$, RACHEL VOLBERG ${ }^{11} \odot$, \\ DOUGLAS WALKER $^{12}$ (i) and ROBERT J. WILLIAMS ${ }^{13} \odot$
}

\author{
${ }^{1}$ Gambling Research Exchange, Guelph, ON, Canada \\ ${ }^{2}$ Deptartment of Recreation \& Leisure Studies, University of Waterloo, Waterloo, ON, Canada \\ ${ }^{3}$ Faculty of Health and Environmental Sciences, Auckland University of Technology, Auckland, \\ New Zealand \\ ${ }^{4}$ School of Global Studies, University of Gothenburg, Gothenburg, Sweden \\ ${ }^{5}$ Centre for Gambling Research at UBC, Department of Psychology, University of British Columbia, \\ Vancouver, BC, Canada \\ ${ }^{6}$ Department of Psychology, University of Calgary, Calgary, AB, Canada \\ ${ }^{7}$ School of Northern and Community Studies, Laurentian University, Sudbury, ON, Canada \\ ${ }^{8}$ Campbell Family Mental Health Research Institute, Centre for Addiction and Mental Health, \\ Toronto, ON, Canada \\ ${ }^{9}$ Department of Psychiatry, University of Toronto, Toronto, ON, Canada \\ ${ }^{10}$ Public Health Agency of Sweden, Östersund, Sweden \\ ${ }^{11}$ School of Public Health and Health Sciences, University of Massachusetts Amherst, Amherst, \\ MA, USA \\ ${ }^{12}$ Department of Economics, College of Charleston, Charleston, SC, USA \\ ${ }^{13}$ Faculty of Health Sciences, University of Lethbridge, Lethbridge, AB, Canada
}

Received: September 5, 2019 • Revised manuscript received: January 10, 2020; March 19, 2020 • Accepted: April 5,

2020 • Published online: June 16, 2020

*Corresponding author. Gambling
Research Exchange, 55 Wyndham St.
N., Suite 204A, Guelph, 0N, N1H 7T8,
Canada
E-mail: margo@greo.ca.
Tel.: +1 519763 8049, x101.

\begin{abstract}
Background and aims: The Conceptual Framework of Harmful Gambling moves beyond a symptomsbased view of harm and addresses a broad set of factors related to the risks and effects of gambling harmfully at the individual, family, and community levels. Coauthored by international research experts and informed by multiple stakeholders, Gambling Research Exchange (GREO) facilitated the framework development in 2013 and retains responsibility for regular updates and mobilization. This review article presents information about the revised version of the Conceptual Framework of Harmful Gambling completed in late 2018. Methods: We describe eight interrelated factors depicted in the framework that represent major themes in gambling ranging from the specific (gambling environment, exposure, gambling types, and treatment resources) to the general (cultural, social, psychological, and biological influences). After outlining the framework development and collaborative process, we highlight new topics for the recent update that reflect changes in the gambling landscape and prominent discourses in the scientific community. Some of these topics include social and economic impacts of gambling, and a new model of understanding gambling related harm. Discussion and conclusions: We address the relevance of the CFHG to the gambling and behavioral addictions research community. Harm-based frameworks have been undertaken in other areas of addiction that can both inform and be informed by a model dedicated to harmful gambling. Further, the framework brings a multi-disciplinary perspective to bear on antecedents and factors that cooccur with harmful gambling.
\end{abstract}




\section{KEYWORDS}

conceptual framework, harmful gambling, public health, social determinants of health, interdisciplinarity, harmful gambling antecedents

\section{BACKGROUND AND AIMS}

Gambling is a popular leisure activity with a long history, which today-legally permitted or not-is present in almost all societies of the world. Gambling participation rates vary by jurisdiction. For example, in Ontario, Canada, $82.9 \%$ of the general population reported past-year gambling participation (Williams \& Volberg, 2013) compared to $66.6 \%$ in the neighboring province of Quebec (Kairouz, Nadeau, \& Robillard, 2014), a figure that is more similar to Australia where the national participation rate is $63.9 \%$ (Dowling et al., 2016a). Although many people gamble recreationally with no apparent detriments, gambling may cause negative repercussions for others and lead to gambling addiction. Internationally, past-year rates of problem gambling among the adult population range from $0.1 \%$ to $5.8 \%$ (Calado \& Griffiths, 2016). These prevalence rates do not fully capture the amount of gambling-related harm experienced by people who gamble, and others negatively affected by gambling. From a public health perspective, it has been claimed that a substantial proportion of the harm experienced by gamblers is attributable to people identified as low risk due to their substantially higher numbers when compared to those in the problem gambling category (Browne et al., 2016). This is, however, a controversial claim because it relies on a definition of "harm" that includes consequences of gambling that some may perceive as inconveniences or opportunity costs (Browne \& Rockloff, 2017; Delfabbro \& King, 2017, 2019).

Various models have been created to help understand gambling-related problems and the individual and environmental differences that may influence them, but to our knowledge, no one model that spans disciplines, cultures, and jurisdictions has comprehensively addressed harmful gambling. The Conceptual Framework of Harmful Gambling (Abbott et al., 2018a), or "the Framework", attempts to do so by addressing antecedents and factors associated with harmful gambling.

The Framework was created by a team of international experts whose research focus, at least in part, is on the risks and effects of harmful gambling. It acts as both a conceptual model and a resource to guide understanding of factors associated with harmful gambling. The document is now in its third edition, having been revised most recently in November 2018. It is freely available on the Gambling Research Exchange (GREO) website (www.greo.ca) both as a PDF and as an interactive website. Although uptake and interest in the Framework has grown since the first edition was published in 2013, the model has not yet been presented in the academic literature. We address this gap by outlining the Framework and highlighting new additions and changes to the third edition. We begin by providing a background to the Framework development, then describe its structure, and conclude by addressing the relevance of the Framework to gambling and behavioral addictions researchers.

\section{About the framework}

The Framework development was undertaken initially in 2011 by the Ontario Problem Gambling Research Centre (OPGRC), which subsequently became GREO in 2013, to address the need for a comprehensive framework of harmful gambling that incorporates multidisciplinary perspectives. The aim was to "develop a clear, comprehensive, and internationally relevant conceptual framework that would address a broad set of factors related to the risks and effects of harmful gambling at the individual, family, and community levels" (Abbott et al., 2018a, p. 2). More specifically, the objectives were:

1. To reflect current knowledge (across existing models and disciplines) as it relates to factors associated with harmful gambling;

2. To assist stakeholders across the gambling landscape to better understand the complex dynamics involved in harmful gambling to enable better informed decision making; and,

3. To guide the development of future research programs by identifying areas where research is most needed (Abbott et al., 2018a, p. 2).

The Framework is intended to inform a wide stakeholder audience by presenting high-level factors that contribute to or influence harmful gambling, and demonstrate the complexity of harmful gambling by showing how the factors are interrelated (Abbott et al., 2018a, p. 2). In this way, it can help to enable evidence-based decision making and guide research programs. Although the Framework intent is to address factors related to harmful gambling at multiple levels, it is somewhat limited at present by the dominance of psychological research focused at the individual level (Baxter, Hilbrecht, \& Wheaton, 2019). This may be starting to shift, however, as more researchers approach harmful gambling from a public health perspective that examines multiple contributing factors at the population level (e.g., see Browne et al., 2016; Korn \& Shaffer, 1999; Wardle, Reith, Langham, \& Rogers, 2019).

Harmful gambling can be challenging to define, both conceptually and empirically (for a more in-depth discussion see Browne, Greer, Rawat, \& Rockloff, 2017; Browne \& Rockloff, 2017; Delfabbro \& King, 2019; Rawat, Browne, Bellringer et al., 2018). A broad definition of harmful gambling advanced for the Framework is:

\footnotetext{
... any type of repetitive gambling that a person engages in that leads to (or aggravates) recurring negative consequences, such as significant financial problems, addiction, or physical and mental health issues. Additionally, the gambler's family, social network, and community may also experience negative effects. The degree of harm can range from inconsequential, to transient, to significant; harm can be episodic or chronic. (Abbott et al., 2018a, p. 4)
} 
The Framework is authored by a multidisciplinary international panel of experts, drawing upon their individual expertise and general knowledge of gambling harm. Authors are listed alphabetically to indicate their shared contributions in refining the framework and shaping its direction. For the 2018 edition, the panel includes Max Abbott (Auckland University of Technology), Per Binde (University of Gothenburg), Luke Clark (University of British Columbia), David Hodgins (University of Calgary), Mark Johnson (University of Alberta), Darrel Manitowabi (Laurentian University), Lena Quilty (Centre for Addiction and Mental Health), Jessika Spångberg (Public Health Agency of Sweden), Rachel Volberg (University of Massachusetts), Douglas Walker (College of Charleston), and Robert Williams (University of Lethbridge). From the outset, the Framework has been a collaborative document that avoids attribution of sections to panel members.

A core group of panel members has been involved since the Framework's inception. When it was first published (Abbott et al., 2013), there were seven panel members. At the time of the 2015 revision (Abbott et al., 2015b), the number increased to 11. The third edition (Abbott et al., 2018a) also has 11 contributors, with three new members joining to lend their expertise when three others were unable to continue. GREO retains responsibility for updating the document to reflect current issues and new developments, organizes the revision process, and is responsible for knowledge translation and exchange (KTE). KTE refers to the process of distilling and disseminating knowledge so that it can be used by broader audiences to take action and make decisions (Straus, Tetroe, \& Graham, 2009).

\section{Revision process}

The Framework is a living document intended to be reviewed, revised, and updated every few years. Early in the revision process, panel members who contributed to earlier editions shared their thoughts about content and format, uptake and use by various audiences, what worked (and did not work) well in the previous revision process, along with suggestions for strengthening the Framework.

Since a goal was to enhance the multidisciplinary perspective and supporting documentation, authors were encouraged to draw from domains that had not previously been well represented, such as social geography, public health, and cultural studies. GREO staff conducted a bibliometric analysis of the previous edition to identify factors that would benefit from an increase in supporting materials. To enhance cohesiveness, panel members focused their contributions on harmful gambling specifically, and prioritized findings from meta-analyses and systematic reviews to ensure robustness of the evidence.

Accessibility of the Framework to multiple audiences was a priority. The document was reviewed and edited by the GREO team to ensure plain language and a consistent, common voice. As part of the accessibility update, the citation style was changed from APA 6th edition to a less obtrusive style, with links to plain language summaries for cited articles, when available.

\section{FRAMEWORK STRUCTURE}

The framework is comprised of eight factors that are grouped into two topical sets (see Fig. 1). The factors represent the main antecedents or conditions that can contribute to harmful gambling. Each consists of two to nine subfactors that reflect major themes of the topic area. For detailed factor and subfactor descriptions, refer to the Framework document (Abbott et al., 2018a), and for a general summary, to the online interactive version (GREO, 2018). Each set of factors is outlined separately below, with brief descriptions of each related subfactor and more detail

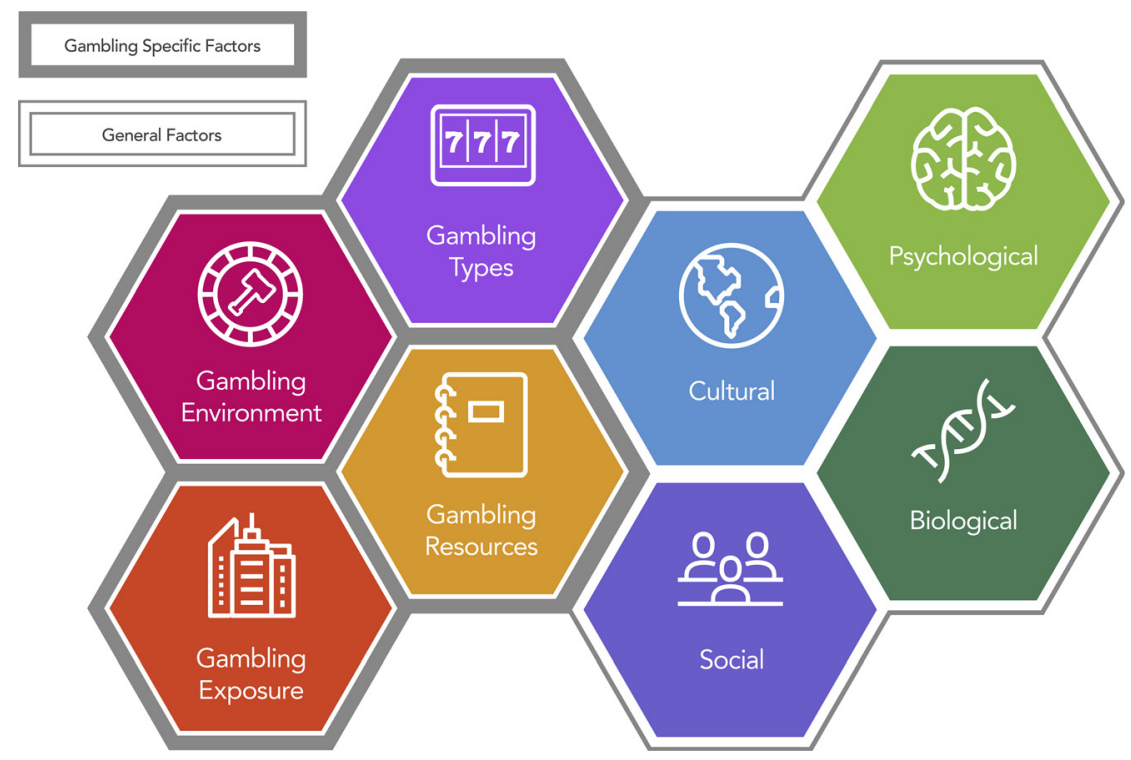

Figure 1. Conceptual Framework of Harmful Gambling 
for those that are new or substantially expanded in the 2018 edition.

\section{Gambling-specific factors}

The four factors included in this set represent major areas of research that have emerged in gambling studies. They include the Gambling Environment, Gambling Exposure, Gambling Types, and Gambling Resources. As mentioned, the factors are interrelated and relevant to the General Factors, which will be discussed later.

Gambling environment. The environment in which gambling occurs is subject to government regulation and oversight as well as consumer demand, both of which differ by jurisdiction. This factor is linked to institutional or community level influences that can influence the likelihood of harmful gambling. These Gambling Environment subfactors are included from earlier framework editions: economics, the socio-political environment, public policy, and culture of social responsibility. Economics of gambling is examined at the macro level to understand how growth in gambling, especially casinos, can impact wages, tax revenue, employment, and other industries (e.g., see Borg, Mason \& Shapiro, 1993; Cotti, 2008; Goodman, 1994; Grinols \& Omorov, 1996; Humphreys \& Marchand, 2013; Walker \& Jackson, 2011). At the microeconomic level, attention is given to monetary estimates of the social costs of gambling and individual outcomes related to bankruptcy, crime, debt, and decreased productivity (e.g., see Grote \& Matheson, 2013; Thompson, Gazel \& Rickman, 1997; Walker, 2010; Walker \& Barnett, 1999), although monetary estimates of social costs remain difficult to ascertain due to discrepancies in definition and measurement (Grinols, 2004; Walker \& Barnett, 1999), including accounting for the effects of comorbid conditions (Walker, 2003). The socio-political environment explores how social, political, and economic systems influence where, how, and to what extent gambling is offered in different jurisdictions. Public policy discusses the need for policy focused on promoting health and wellbeing with an emphasis on preventing and reducing harm, while at the same time recognizing vested interests of government and operators in revenue generation. Culture of social responsibility refers to attitudes and approaches adopted by governments and industry to balance revenue generation with socially responsible practices to prevent or reduce harmful gambling.

New to the third edition are discussions of responsible gambling, social and economic impacts, and low-risk limits. The term Responsible gambling (RG) refers to tools and approaches associated with gambling provision that have the potential to reduce harmful gambling (Abbott et al., 2018a, pp. 20-21). RG practices are broadly informed by the Reno Model (Blaszczynski et al., 2011; Blaszczynski, Ladouceur, Nower, \& Shaffer, 2008; Blaszczynski, Ladouceur, \& Shaffer, 2004; Collins et al., 2015), which is based on two main principles: the decision to gamble is an individual's choice, and people need adequate information to make an informed choice. The model has been criticized in recent years for its focus on individual responsibility and people with gambling problems (Hancock \& Smith, 2017), rather than adopting a broader public health perspective on population harm (Abbott, 2017a). Moving beyond issues of individual, operator, and government responsibility, Nower and Caler (2018) present a syndemic approach to RG that recognizes the influence of multiple interacting comorbid conditions and social and environmental factors that exacerbate harmful gambling, as well as the importance and challenges of multiple stakeholder involvement to address it.

Social and economic impact examines the effectiveness of policies or interventions by considering both positive and negative impacts. Positive social and economic impacts can include increased government revenue, more entertainment options, better infrastructure, and higher property values due to the vicinity of new gambling venues. Conversely, new gambling opportunities have been linked to higher rates of gambling problems and related harms, most of which are not accounted for because people with gambling problems rarely seek treatment (Williams, Stevens, \& Nixon, 2011a). Further, non-monetary impacts such as relationship breakdown or job loss due to gambling are often challenging to measure.

Low-risk limits are being developed in response to findings identified in international longitudinal cohort studies that consistently indicate that the intensity of gambling engagement can predict at-risk and problem gambling (Currie, \& the Lower Risk Gambling Guidelines Scientific Working Group, 2018). Like the low risk alcohol consumption guidelines already adopted by several jurisdictions, low risk gambling guidelines could provide 'safe' thresholds to prevent or mitigate harmful gambling based on gambling frequency, expenditure, and percentage of household income spent gambling (Currie et al., 2017). These guidelines are not without critique, such as having no standard unit of gambling as there is for alcohol, or that different thresholds could apply depending on game type or population group (Abbott, 2017b). Although these considerations need to be addressed, low risk limits remain a promising area for further exploration.

Gambling exposure. Exposure to gambling is conceptualized as the extent to which people or population subgroups come into contact with and are influenced by the availability of gambling activities (Abbott, 2007). Subfactors retained from previous Framework editions are the gambling setting, accessibility, adaptation, and marketing and messaging. Gambling setting discusses land-based venues and Internet gambling settings with reference to factors implicated in harmful gambling such as availability of alcohol, access to credit, and being able to play on multiple sites or games simultaneously. Accessibility explores how greater access to gambling venues and the rise in online gambling is linked to increased participation, spending, and harm. Evidence on gambling expansion is limited though, and a recent metaanalysis suggests that the outcomes may be more complex than originally thought since almost two-thirds of studies 
reported no observable detriments (LaPlante, Gray, Williams, \& Nelson, 2018). The Adaptation section examines both the availability (or exposure) hypothesis, based on earlier alcohol research, and the adaptation hypothesis (Abbott, 2006). The availability hypothesis suggests that expansion of gambling opportunities leads to increased participation and harm, while the adaptation hypothesis predicts an initial increase, then a plateau, followed by reduced rates of harmful gambling after populations have been exposed over time. Marketing and messaging explores advertising influences and media representations of gambling on perceptions of gambling, on the behavior of people with at-risk or problem gambling, as well as their role in sustaining a company's revenue and attracting new customers.

A new subfactor, Convergence of gaming and gambling, addresses the growing online market and blurred boundaries between video gaming and gambling. In general, gaming and gambling differ in that positive outcomes in gaming are due mostly to skill, whereas for gambling they are attained mostly by chance. Confusing matters further is that industry operators often use the terms gaming and gambling synonymously, perhaps to avoid negative perceptions associated with gambling (Abbott et al., 2018a, p. 41). Convergence is demonstrated in several areas. Online betting on sport events, for example, has extended to daily fantasy sports and esports. The media used by players is also converging from video consoles to online games, with numerous crossovers between gaming and gambling in products, networks, and platforms. This extends both the reach of these activities and the potential for harm to larger audiences (Gainsbury et al., 2015b). Gaming-like gambling refers to the inclusion of gaming activities in gambling, such as an element of skill or themes from social media games into an Electronic Gambling Machine (EGM), which can be effective in attracting younger players (Gainsbury, King, Abarbanel, Delfabbro, \& Hing, 2015a). Gambling-like gaming, on the other hand, includes elements of gambling in video games. This has raised concerns about a potential link between video games and harmful gambling. Mini-games like a casino or poker game, for example, may be set within a game as a side attraction and mirror the spaces, contexts, and aesthetics of play of real life gambling activity. In this way, players become well versed in gambling, but without the financial consequences (Johnson, 2018). They may subsequently move on to actual gambling. Loot boxes are a second and perhaps more controversial form of gambling-like gaming. Players can purchase virtual containers of items to enhance (or advance) game play without knowing what is in them, and with unknown odds of obtaining valuable items determined when the loot box is opened rather than when manufactured (Brooks \& Clark, 2019; Drummond \& Sauer, 2018). Research related to harmful gaming is limited at present, but no doubt will expand as the popularity of online gaming grows.

Gambling types. Many different forms of gambling can be accessed at land-based venues or online. They are broadly grouped into two categories: games of chance that are nonstrategic and have outcomes determined purely by chance, and games of skill that involve both strategy and chance. This factor includes two subfactors, with no new additions in 2018. Structural characteristics refer to the parameters and technologies of games. They include features such as timing and reward parameters. For example, lotteries have a long timing delay to the reward outcome compared to EGMs where there is little delay and immediate opportunities to bet again. While participation in 'continuous' gambling forms including EGMs is more strongly associated with harm, lottery play can have harmful outcomes. Some people may spend substantial amounts of money on lottery tickets when they are in difficult economic situations with the unrealistic hope of winning large sums of money (Beckert \& Lutter, 2013). Other structural characteristics of EGMs can facilitate stronger engagement and the potential for harm such as "bonus rounds" featuring free spins (Taylor, Macaskill, \& Hunt, 2017) and "losses disguised as wins", where a payout is less than the initial wager (Dixon, Harrigan, Sandhu, Collins, \& Fugelsang, 2010). Motivational characteristics was termed "Motivations for gamblers" in earlier editions. This change in language allows a focus on different motivations between gambling types rather than gambling in general. Games such as Mahjong and poker can satisfy social needs depending on game type, but evidence is mixed in terms of the relationship to harmful gambling (Quinlan, Goldstein, \& Stewart, 2014). On the other hand, high stakes casino games are associated with thrill or sensation-seeking motivations, and the link to harmful gambling is well established (Balodis, Thomas, \& Moore, 2014; Bonnaire, Bungener, \& Varescon, 2006).

Most researchers would acknowledge the differential levels of harm among gambling forms; however, people who take part in several gambling types often gamble more heavily and are at a greater risk of experiencing harm (Binde, Romild, \& Volberg, 2017). This may be because versatility in gambling is closely linked to the intensity of gambling, and because of exposure to a greater variety of gambling risk factors, associated with the different gambling forms. The evidence base includes findings from methodologically strong prospective general studies across multiple jurisdictions (e.g., see Abbott, Bellringer, Garrett, \& MundyMcPherson, 2015a; Abbott, Romild \& Volberg, 2018b; Billi, Stone, Marden, \& Young, 2014; el-Guebaly et al., 2015). Such data are usually correlational, showing that some forms of gambling are associated more closely with harmful gambling behavior than other forms. This may be because these forms tend to create harmful gambling or that they are particularly attractive to people who already have a gambling problem - in both cases in force of their structural characteristics, social contexts, and other factors discussed in the Framework. The association between a particular form of gambling and gambling harm is not absolute but relative to other forms and depends on the mix of games available on a particular gambling market.

Gambling resources. This factor provides information about harm reduction resources to prevent harmful 
gambling from developing, and interventions to reduce it once it happens. Few people seek gambling help due to psychological issues and/or a lack of resources. Service access and use is the first subfactor. It examines the extent to which the environment, including treatment and support systems, and psychological factors like shame or stigma can vary based on social and cultural values. Harm reduction, prevention, and protection discusses the tensions between policies that limit gambling exposure and the marketing and advertising that promotes it. It also explores different programs like self-exclusion and their relative effectiveness. Risk assessment outlines how tools developed to assess the risk of various gambling forms can help to identify game types with greater potential for harmful gambling. Interventions is the final subfactor, with sections on psychotherapy such as Cognitive Behavioral Therapy (CBT) (Gooding \& Tarrier, 2009); pharmacotherapy, which can be particularly helpful for people with comorbid disorders (Yip \& Potenza, 2014); brief interventions (Quilty, Wardell, Thiruchselvam, Keough, \& Hendershot, 2019); and, mutual support (Binde, 2011) such as Gamblers Anonymous.

A section on self-help as an intervention was more fully expanded in 2018. Specifically, it moves beyond tools like workbooks and manuals or audio and video recordings to include more information about online resources such as computer or web-based programs. Although nascent when the previous edition was written, studies of online and mobile treatment interventions are rapidly increasing. The findings suggest that this type of treatment is generally less effective than in-person forms, perhaps due to the short length of treatment when compared to longer duration treatments like CBT. Still, recent systematic reviews generally support the value of online and telephone treatments (Chebli, Blaszczynski, \& Gainsbury, 2016; van der Maas et al., 2019). Some reasons may be that they are inexpensive, easily accessible, and provide anonymity. Given the rapid growth of online and telephone treatment options, evaluation studies are expected to continue to expand our understanding of their efficacy.

\section{General factors}

The four general factors are Cultural, Social, Psychological, and Biological. Each represents a disciplinary area. They can be either directly or indirectly related to the harmful gambling life course.

Cultural factors. Culture is a central influence on values and meanings which, in turn, affects gambling attitudes, participation, and prevalence. It can play a role in the extent of harmful gambling, as well as its severity, consequences, and treatment. There are six subfactors: ethnicity and traditions, socio-cultural attitudes, religion and other belief systems, Indigenous Peoples, gambling cultures, and gender. The first three were carried forward from the 2015 edition with minor updates only. Ethnicity and traditions acknowledges ways in which perspectives on gambling vary according to culture with different emphases on attributes such as luck and patterns of probabilistic thinking (e.g., Forrest \& Wardle, 2011; Kim, 2012). It also reviews the influence of immigrant and refugee experiences on harmful gambling (e.g., Jacoby et al., 2013). Socio-cultural attitudes examines changes in societal attitudes toward gambling that can be linked to dominant norms and values. Attitudes may shift from disapproving to permissive and accepting depending upon broader socio-economic changes, and they also vary by political orientation, social class, and demographics (e.g., Beckert \& Lutter, 2013; Binde, 2009). Religion and other belief systems influence gambling behavior through specific prohibitions or beliefs, as demonstrated in monotheistic religions such as attitudes of condemnation found in Mormonism and Jehovah's Witnesses, whereas other religious groups like Roman Catholicism are more accepting (Abbott et al., 2018a, p. 76). Feelings of spiritual faith are also connected to overcoming problem gambling, such as the Serenity Prayer that is part of the Gamblers Anonymous self-help treatment program (Ferentzy, Skinner \& Antze, 2010).

The last three subfactors are more fully developed in the 2018 edition. Indigenous Peoples was updated to include greater context regarding the colonized and political position of Indigenous Peoples. Within Indigenous cultures, gambling has been variously approached as a social and recreational or ritual or spiritual activity (Williams, Rehm, \& Stevens, 2011b). It is interconnected in a complex way with other societal and cultural aspects. Caution must be used when reviewing early accounts of Indigenous gambling since they reflect an early missionary and settler lens, rather than the perspective of Indigenous Peoples (Abbott et al., 2018a, p. 72). It is also important to remember that there are vast differences among Indigenous groups. Compared to the general population, there are varying results for participation frequency, gambling preferences, and expenditures. Still, many studies have found that Indigenous Peoples have higher rates of problem gambling and high levels of gambling-related harm (Breen \& Gainsbury, 2013; Mason, 2017; Williams, Volberg, \& Stevens, 2012). Thought must also be given to the economic impacts of gambling revenue on Indigenous communities, which merits more holistic reflection (Manitowabi, 2011; Moellman \& Mitra, 2013).

Gambling cultures was briefly discussed in the Gambling Types factor in the first two editions, then moved to the Cultural factor in 2018, highlighting the need for more research from a cultural studies perspective. It discusses subcultures with languages, behavioral norms, and local lore that may arise over time among gamblers involved in specific games (e.g., Fox, 2005; Krauss, 2010; Puri, 2014; Rosecrance, 1986). Players typically see one another regularly and become part of each others' social worlds (Ocean \& Smith, 1993). This may make it more difficult for gamblers to limit their participation since the activity becomes an integral part of their social network.

Gender began as a subfactor of Biological Factors in the first edition and was moved to Cultural Factors in the second edition since the cultural, ethnic, and social class influences of gender are considered more important in shaping 
gambling behaviors and attitudes than biological sex. The subfactor was expanded substantially in the 2018 revision to review the main themes that emerge in this area of study. We know, for example, that women are more likely to gamble as a stress coping mechanism to escape negative events (Boughton, 2002; Dow Schull, 2002), while men may participate in high-risk gambling to enhance social capital in a culture of machismo (Cassidy, 2014; Hunt \& Gonsalkorale, 2018). Further, male gender is a risk factor for problem gambling (Dowling et al., 2017). Gender differences in gambling and problem gambling begin early and are apparent even among adolescents (Calado, Alexandre, \& Griffiths, 2017; Molinaro et al., 2018). These gendered patterns may be linked to expectations surrounding work and family roles. It may also be that gender acts as a proxy for levels of risk behavior, with some of these behaviors playing a stronger role than gender itself (Blanco et al., 2015; Romild, Svensson, \& Romild, 2017).

Social factors. Human activity is influenced by social interactions at the interpersonal level, as well as patterns, norms, and rules of conduct at the structural level. These interactions can affect perceptions and experiences of gambling and have been linked to both support and interference when trying to change harmful behaviors. Some of the six subfactors were expanded substantially to include new information, but no new subfactors were added.

Social demographics, like younger age, male gender, and lower socioeconomic status have been identified as risk factors of an increased likelihood of harmful gambling (Abbott, Volberg, Bellringer, \& Reith, 2004). Added to this section is new information about gambling and homelessness, including lasting effects of housing insecurity on gambling behaviors (e.g., Holdsworth \& Tiyce, 2013; Matheson, Devotta, Wedaferew, \& Pedersen, 2014; Sharman, Dreyer, Clark, \& Bowden-Jones, 2016). Family and peer gambling involvement addresses the role of family and peer relationships in harmful gambling. It ranges from the effect of parental participation and parenting style on future gambling behaviors, to the role of antisocial peers for adolescents (e.g., Dowling et al., 2017; Saugeres, Thomas, \& Moore, 2014). New in 2018 is a more in-depth discussion on harms experienced in intimate partner relationships, as problem gambling is linked to higher rates of intimate partner violence (Merkouris, Thomas, Browning, \& Dowling, 2016). The education system presents a valuable opportunity for formal learning about gambling risk factors and harms, especially with increased exposure of adolescents to online gaming and gambling. Curricula have been developed for the whole student body and specific subgroups, but evaluation is limited. Further, educators may need convincing that gambling is an important concern (Derevensky, St-Pierre, Temcheff, \& Gupta, 2014; Ladouceur, Ferland, Côté, \& Vitaro, 2004). The neighborhood in which one resides can limit or increase gambling opportunities since such opportunities are not evenly distributed across neighborhoods (Pearce, Mason, Hiscock, \& Day, 2008; Rintoul, Livingstone, Mellor, \& Jolley, 2012).
Neighborhoods with low social capital and greater social disadvantage tend to have more gambling opportunities and more problem gambling (Griswold \& Nichols, 2006; Livingstone, 2001; Lussier, Derevensky, Gupta, \& Vitaro, 2014). Stigmatization is a form of social control used to exclude and marginalize people. People who gamble, and especially those who experience harm, are often stereotyped as greedy, irrational, and irresponsible (Horch \& Hodgins, 2013). People with gambling problems experience stigma at a similar level to those with schizophrenia or alcohol use disorder (Horch \& Hodgins, 2008) and some demographic groups, such as women, may feel more stigma than men (Afifi, Cox, Martens, Sareen, Ens, 2010). Deviance is behavior contrary to social norms and expectations. This behavior is often linked to mental health and illness. The 'medicalized' perspective of problem gambling as deviant began in the 1970s and still persists (Castellani, 2000; Rosecrance, 1985). This subfactor was expanded to include new information on gambling and crime. For example, the need to obtain money for gambling may cause people to commit crimes. Or, it can be seen as one of several social and environmental factors that underlie criminal behavior more generally (Williams, Royston, \& Hagen, 2005). Also provided is information about criminogenic problem gambling (e.g., Banks \& Waugh, 2019; Dowling et al., 2016b) and gambling-related embezzlement at work (e.g., Binde, 2016).

Psychological factors. This factor explores how individual differences and other psychological disorders and conditions may make people more susceptible to harmful gambling. With the greater volume of research that can be assigned to the psychological factors (Baxter et al., 2019; Hancock \& Smith, 2017), it is perhaps not surprising that it has the greatest diversity of subfactors. Six of the nine subfactors were carried forward with updated evidence, two underwent more substantial revisions, and one new subfactor was added.

Personality and temperament is concerned with individual feelings, thoughts and actions. For instance, traits such as novelty-seeking (Black et al., 2015) and low behavioral control (Savage, Slutske, \& Martin, 2014) are both associated with a greater likelihood of harmful gambling behavior. Personality disorders often co-occur with harmful gambling as well (Dowling et al., 2015). Coping styles are important to consider in harmful gambling. People who use avoidant coping strategies to manage emotional difficulties are more likely to have gambling problems than others who use different strategies like a problem-solving approach (Borsoi \& Toneatto, 2003). Selfperceptions can influence the likelihood of harmful gambling, and having gambling problems can, in turn, affect selfperception. For example, people with a financially focused selfconcept are more likely to experience harmful gambling (Tabri, Wohl, Eddy, \& Thomas, 2016). Among those with gambling problems, self-concept can be changed in a negative way (Wohl et al., 2018). Social learning relates to the influence of the social environment on gambling behaviors. Experiences of having personal relationships suffer due to harmful gambling, for instance, can lead to little or no gambling. Lifespan development explores how age and life events and circumstances are 
associated with harmful gambling. It recognizes age-related risk, and that factors contributing to harmful gambling can change over the life course. Subjective well-being tends to decrease as risk levels for harmful gambling increase (Hilbrecht \& Mock, 2019; Tang \& Oei, 2011). People with gambling problems experience more stress (Biback \& Zack, 2015), which contributes to negative feelings of well-being.

The comorbid disorders subfactor was expanded in 2018 to more fully acknowledge high rates of comorbid mental health conditions with problem gambling. About threequarters of people who seek treatment for gambling problems also report a mood disorder or substance use issues (Dowling et al., 2015). There is some discussion of temporal sequencing in relation to which condition was present firstgambling problems or the mental health disorder-and it appears that gambling problems can be present before, during, or after the onset of the disorder or substance use issue (Afifi, Nicholson, Martins, \& Sareen, 2016; Hartmann \& Blaszczynski, 2018). Judgment and decision making was also expanded. It considers how people make decisions by evaluating risks and choosing between options. Some decision making processes associated with harmful gambling include probability weighting (Ligneul, Sescousse, Barbalat, Domenech, \& Dreher, 2013), loss aversion (Genauck et al., 2017), and relying on heuristics (d'Astous \& Di Gaspero, 2015). This section also addresses gambling-related cognitive distortions such as illusion of control and the Gamblers' Fallacy (Toneatto \& Nguyen, 2007). These faulty beliefs can be encouraged by game design, and often result in gambling more than intended. Adverse childhood experiences is the new subfactor. It was added to reflect the strong link between early adversity, such as neglect, parental substance use, or traumatic experiences and the development of future harmful gambling. People who experience greater adversity in childhood have a higher risk of harmful gambling (Poole, Kim, Dobson, \& Hodgins, 2017).

Biological factors. Harmful gambling is influenced by differences in brain function and structure. What is less certain is whether neurobiological differences are already present or appear as a consequence of harmful gambling. This factor has two subfactors. Both were updated but not extensively revised in 2018.

Genetic inheritance explores how heritable traits interact with environmental influences to elevate the risk of developing gambling problems. Evidence is presented on studies using twin pairs indicating that variance in gambling problems is associated with a genetic component as well as non-shared environmental influences (Slutske, Zhu, Meier, \& Martin, 2010). There is also a discussion of specific gene variants associated with gambling problems, including genes affecting dopamine and serotonin transmission, but more research is needed.

Neurobiology explores differences between people with and without gambling problems relative to brain structure and functioning. For example, people with gambling problems often show altered functioning in the brain system related to inhibitory control, reward processing, and riskbased decision making (Kovacs, Richman, Janka, Maraz, \&
Ando, 2017; Limbrick-Oldfield, van Holst, \& Clark, 2013). New information was added about the potential of naltrexone, and forms of brain stimulation, such as direct current stimulation (Dickler et al., 2018) and transcranial magnetic stimulation (Zack et al., 2016), as neurological treatments for problem gambling.

\section{Additional resources}

The Framework document describes each factor and related subfactors in much greater detail, supported by extensive reference lists that include supplementary links to research summaries produced by GREO should readers wish to pursue any topic further. Additional materials that have informed thinking about the model are presented in separate sections described below.

Summary of existing research that informed our work. The Framework builds on the work of several existing models and theories. These have played a foundational role not only in the development of the Framework, but also in the field of Gambling Studies. Summaries of key points are provided for each, with the hope that they will become a useful starting point for future studies and encourage researchers to consider how they may be applied or extended as new and relevant information becomes available.

Longitudinal cohort studies. In the 1990s, researchers began conducting prospective studies that would allow greater insights regarding harmful gambling, including the etiology of problem gambling and transitions over time. From Canada, they include the Leisure, Lifestyle, and Lifecycle Project (el-Guebaly et al., 2015) and the Quinte Longitudinal Study (Williams et al., 2015). The other three studies described in this section are the Swedish Longitudinal Gambling Study (Romild, Volberg, \& Abbott, 2014), the Victorian Gambling Study (Billi, Stone, Marden, \& Yeung, 2014) undertaken in Australia, and the New Zealand National Gambling Study (Abbott, Bellringer, Garrett, \& Kolandai-Matchett, 2017). While the preceding studies are now complete, the Massachusetts Gambling Impact Cohort Study (Mazar, Volberg, Williams, Stanek, \& Zorn, 2019) is still underway. Findings common to the six comprehensive studies are presented, including predictive factors that are strongly associated with harmful gambling, and discussed in relation to specific Framework factors.

Topics for future investigation. Based on knowledge gaps identified in the Framework, topics of research that could strengthen the Framework and our understanding of harmful gambling are suggested. In the 2018 edition, they are listed by framework factor, along with a final subsection specific to research design.

\section{Ethics}

Review by an Institutional Review Board was not required. 


\section{ADDED VALUE TO CURRENT RESEARCH}

There are six primary areas where the Framework adds value to the research landscape (see Abbott et al., 2018a, pp. 4-5). First, it focuses on harm at all levels including the individual, significant others, communities, and society overall. This represents a shift from the dominant psychological approach that concentrates on individual symptomology and treatment (Baxter et al., 2019; Eber \& Shaffer, 2000; Hancock \& Smith, 2017; Shaffer, Stanton, \& Nelson, 2006). Second, it demonstrates areas of robust evidence and identifies knowledge gaps. Third, because the Framework highlights the complexity of harmful gambling and interlinkages between various factors without adhering to any established model, it acts as an impetus for researchers to pursue theory-driven research to advance understanding of harmful gambling at multiple levels. Fourth, it promotes a harm reduction approach whereby measures beyond abstinence are examined and there is a stronger emphasis on protection measures that can occur through, for example, regulation, product design, and the gambling policy environment. Fifth, the Framework considers both benefits and costs to gamblers and others, which encourages discussions of safer gambling and how to best provide it, although research on benefits is limited at present. Finally, harm-based frameworks have been undertaken in other fields, such as alcohol and mental health (Substance Abuse and Mental Health Services Association, 2010; World Health Organization, 2018), that can both inform and be informed by a model dedicated to harmful gambling.

\section{DISCUSSION AND CONCLUSIONS}

The Framework was designed to be relevant and accessible to a variety of stakeholder audiences, with a focus on researchers, treatment providers, policy makers, regulators, and the general public. This broad reach means that various groups have used the Framework to address different needs.

Among faculty, it has been useful for teaching at the undergraduate and graduate levels. It can be used as an organizing framework for entire courses or course units. Researchers wishing to provide a general overview of harmful gambling have found it relevant for training Research Assistants since it is accessible, freely available, and comprehensive. Others have used the Framework as a guiding model when developing research proposals to ensure that all potential areas of impact are covered. It also provides quick access to foundational studies in areas of gambling research with which researchers may be less familiar. Stakeholders with clinical responsibilities have used it indirectly as a guide to areas to assess or discuss with clients.

The Framework is also useful for other stakeholders who work in the gambling field but not in harmful gambling. For regulators and operators, for example, the Framework and associated KTE products are a primer for the current issues regarding problem gambling and gambling-related harm.

With regard to other behavioral addictions, the new section Convergence of gaming and gambling is especially relevant to the study of gaming disorder, which is recognized as an addictive behavior in the ICD-11 and as a topic for further study in the DSM-5 (as Internet Gaming Disorder). It highlights the discussion of features of video games that are gambling-like and can contribute to gambling-like harm. Further, the Framework could be used as a blueprint for developing frameworks for other behavioral addictions.

There are some limitations to the Framework. The definition of harmful gambling is broad and cannot completely encompass the full scope of behaviors and outcomes associated with harm. Further, although it purports to address harmful gambling at the individual, family, and community level, much of the present focus remains at the individual level. This will be addressed in future revisions as the evidence base on the effects of harmful gambling at the family and community levels grows. Similarly, we anticipate that more information on both the costs and benefits of gambling will be included as new findings emerge. There are a few areas where further research is urgently needed. More prospective studies from more jurisdictions could advance understanding of the etiology of harmful gambling. It is also worth considering that there are other ways, besides prospective longitudinal studies, of studying etiology, for example qualitative life history approaches (Keatley, Parke, Townsend, Markham, \& Clarke, 2019; Reith \& Dobbie, 2013). To date, these have been largely overlooked. A standardized measurement for harm could be used in population level studies to generate evidence to support policy initiatives. Further, more research could address online gambling. Participation has grown substantially in recent years and there is much to learn in terms of harm, treatment, and other factors that may diverge from understandings based on land-based activities.

In summary, the Framework is a unique summary of the literature in specific areas of harmful gambling, created by international experts who are mindful of the quality of the evidence. It synthesizes the most current and robust findings across relatively broad domains of gambling in a way that offers a general overview, while providing enough documentation so that it is clear where more information can be obtained. Further, it highlights the complexity of harmful gambling since a multidimensional perspective is needed for full understanding. This is useful in promoting greater interconnection among academic disciplines, stakeholder sectors, and others concerned with behavioral addictions.

Funding sources: No financial support was received for this review.

Authors' contribution: $\mathrm{MH}$ conceptualized and wrote most of the manuscript. DB wrote the conclusions section and conducted preliminary bibliometric analyses. MA, PB, LC, DH, DM, LQ, JS, RV, DW, and RW co-authored the 3rd edition of the Conceptual Framework of Responsible 
Gambling (Abbott et al., 2018a), and most have been involved in ongoing framework development since the first edition (Abbott et al., 2013). They reviewed the manuscript and provided feedback that was incorporated into it. All authors had access to all documents used in the Conceptual Framework of Harmful Gambling update including bibliometrics, evaluative comments, and administrative information. All authors reviewed and approved the final manuscript.

Conflict of interests: MH has no financial or non-financial conflicts of interest. She has previously received funding from the Alberta Gambling Research Institute (AGRI) for conference travel.

DB has no financial or non-financial conflicts of interest. He has previously received funding from AGRI for research consultation.

MA has no financial or other conflicts of interest to declare. During the past decade his research funding and financial support for academic and consultancy activities have predominantly come from universities and government funded agencies and organisations in New Zealand, Sweden, Canada, China and Australia. He has also received travel and associated support from the World Health Organisation and national NGOs (addictions service providers) in Turkey and Abu Dhabi.

PB has no financial or non-financial conflicts of interest as he has no current or past affiliations with the industry; all his research funding has come from national research councils and from government funded agencies and authorities in Sweden, with the exception of a minor grant in 2014 from the Responsible Gambling Trust in the UK, which is an independent charity receiving economic support from gambling companies.

LC is the Director of the Centre for Gambling Research at UBC, which is supported by the Province of British Columbia government and the British Columbia Lottery Corporation (BCLC). The BCLC is a Canadian Crown Corporation. The Province of British Columbia government and BCLC had no involvement in the ideas expressed herein and impose no constraints on publishing. LC has received travel/accommodation for speaking engagements from the National Center for Responsible Gaming (US) and National Association of Gambling Studies (Australia), and has received honoraria for academic services from the National Center for Responsible Gaming (US) and Gambling Research Exchange Ontario (Canada). He has not received any further direct or indirect payments from the gambling industry or groups substantially funded by gambling.

$\mathrm{DH}$ has no financial or non-financial conflicts of interest. All his research funding over the past 15 years has come from government funded organizations and research councils. He serves on the Scientific Advisory Committee of the International Center for Responsible Gaming but receives no financial support.

DM has no financial or non-financial conflict of interest. All of his previous research funding has come from government sources in Canada.
LQ has received funding during the past 15 years from government or charitable organizations (Canadian Institutes of Health Research, National Institutes of Health, American Foundation for Suicide Prevention, Ontario Brain Institute, Ontario Mental Health Foundation, CAMH Foundation) as well as Gambling Research Exchange Ontario (GREO), Alcohol and Gaming Commission of Ontario (AGCO), and Ontario Lottery and Gaming (OLG). The OLG is a Canadian Crown Corporation and had no involvement in the ideas expressed herein and imposes no constraints on publishing. LQ has received travel/accommodation for speaking engagements from the Alberta Gambling Research Institute (AGRI) and honoraria for academic services from Servier Inc. She has not received any further direct or indirect payments from the gambling industry or groups substantially funded by gambling.

JS has no financial or non-financial conflict of interest. All of her previous research funding has come from government sources in Sweden.

RV has no financial or non-financial conflicts of interest. All of her research funding in the past ten years has come from government funded agencies in the United States, Canada and Europe.

DW has received funding/honoraria during the past 5 years from research organizations including Gambling Research Exchange Ontario, National Center for Responsible Gaming, Responsible Gambling Council, and British Columbia Lottery Corporation. He has also received funding from public firms and industry organizations including: American Gaming Association, Central Atlanta Progress, Chesnoff and Schonfeld, British Columbia Lottery Corporation, Spectrum Gaming Group, Meister Economic Consulting, Strategic Science, Union Gaming Analytics, and Gerson Lehrman Group. Finally, he has earned income from governments/organizations/agencies that are funded directly or indirectly by gambling revenues or taxes, including: South Carolina/College of Charleston, Nevada/University of Nevada Las Vegas, Virginia/Old Dominion University/City of Portsmouth, New York State Gaming Commission, Arkansas/ University of Central Arkansas, and Kansas/Kansas Lottery Gaming Facilities Review Board.

RW has no financial or non-financial conflict of interest to declare during the past 3 years except for a small grant/ contract from Unibet Ltd.

\section{REFERENCES}

Abbott, M. (2006). Do EGMs and problem gambling go together like a horse and carriage? Gambling Research: Journal of the National Association for Gambling Studies (Australia), 18(1), 7.

Abbott, M. (2007). Situational factors that affect gambling behavior. In G. Smith, D. Hodgins, \& R. Williams (Eds.), Research and measurement issues in gambling studies (1st ed., pp. 251-278). San Diego, CA: Academic Press. 
Abbott, M. (2017a). Beyond Reno: A critical commentary on Hancock and Smith. International Journal of Mental Health and Addiction, 15(6), 1177-1186. https://doi.org/10.1007/ s11469-017-9794-3.

Abbott, M. W. (2017b). Commentary on Currie et al. (2017): Lowrisk gambling limits-a bridge too far? Addiction, 112(11), 2021-2022. https://doi.org/10.1111/add.14017.

Abbott, M., Bellringer, M., Garrett, N., \& Kolandai-Matchett, K. (2017). Design and methods of the New Zealand national gambling study, a prospective cohort study of gambling and health: 2012-2019. International Journal of Mental Health and Addiction, 15(6), 1242-1269. https://doi.org/10.1007/s11469017-9843-y.

Abbott, M., Bellringer, M., Garrett, N., \& Mundy-McPherson, S. (2015a). New Zealand national gambling study: Wave 2 (2013) (report number 4). Auckland, New Zealand: Auckland University of Technology, Gambling and Addictions Research Centre.

Abbott, M., Binde, P., Clark, L., Hodgins, D., Johnson, M. A., Manitowabi, D., et al. (2018a). Conceptual framework of harmful gambling: An international collaboration, 3rd ed. ON, Canada: Guelph. Retrieved from: http://www.greo.ca/Modules/ EvidenceCentre/files/Abbott\%20et\%20al\%20(2018)\% 20Conceptual\%20framework\%20of\%20harmful\%20gambling\% 20-\%20third\%20edition.pdf.

Abbott, M., Binde, P., Clark, L., Hodgins, D., Korn, D., Pereira, A., et al. (2015b). Conceptual framework of harmful gambling: An international collaboration, rev. ed. ON, Canada: Guelph. Retrieved from: http://www.greo.ca/Modules/EvidenceCentre/ Details/conceptual-framework-of-harmful-gambling-revisededition.

Abbott, M., Binde, P., Hodgins, D., Korn, D., Pereira, A., Volberg, R., et al. (2013). Conceptual framework of harmful gambling: An international collaboration. ON, Canada: Guelph. Retrieved from: http://www.greo.ca/Modules/EvidenceCentre/ Details/conceptual-framework-of-harmful-gambling.

Abbott, M., Romild, U., \& Volberg, R. (2018b). The prevalence, incidence, and gender and age-specific incidence of problem gambling: Results of the Swedish longitudinal gambling study (Swelogs). Addiction, 113(4), 699-707. https://doi.org/10.1111/ add.14083.

Abbott, M., Volberg, R., Bellringer, M., \& Reith, G. (2004). A review of research on aspects of problem gambling. London, UK. Retrieved from: https://www.gla.ac.uk/media/media_34551_en.pdf.

Afifi, T. O., Cox, B. J., Martens, P. J., Sareen, J., \& Enns, M. W. (2010). The relationship between problem gambling and mental and physical health correlates among a nationally representative sample of Canadian women. Canadian Journal of Public Health-Revue Canadienne De Sante Publique, 101(2), 171-175.

Afifi, T. O., Nicholson, R., Martins, S. S., \& Sareen, J. (2016). A longitudinal study of the temporal relation between problem gambling and mental and substance use disorders among young adults. Canadian Journal of Psychiatry-Revue Canadienne De Psychiatrie, 61(2), 102-111. https://doi.org/10.1177/ 0706743715625950.

Balodis, S. R. S., Thomas, A. C., \& Moore, S. M. (2014). Sensitivity to reward and punishment: Horse race and EGM gamblers compared. Personality and Individual Differences, 56, 29-33. https://doi.org/10.1016/j.paid.2013.08.015.
Banks, J., \& Waugh, D. (2019). A taxonomy of gambling-related crime. International Gambling Studies, 19(2), 339-357. https:// doi.org/10.1080/14459795.2018.1554084.

Baxter, D. G., Hilbrecht, M., \& Wheaton, C. T. J. (2019). A mapping review of research on gambling harm in three regulatory environments. Harm Reduction Journal, 16(1), 12. https://doi. org/10.1186/s12954-018-0265-3.

Beckert, J., \& Lutter, M. (2013). Why the poor play the lottery: Sociological approaches to explaining class-based lottery play. Sociology, 47(6), 1152-1170.

Biback, C., \& Zack, M. (2015). The relationship between stress and motivation in pathological gambling: A focused review and analysis. Current Addiction Reports, 2(3), 230-239. https://doi. org/10.1007/s40429-015-0064-9.

Billi, R., Stone, C. A., Marden, P., \& Yeung, K. (2014). The victorian gambling study: A longitudinal study of gambling and health in victoria, 2008-2012. VIC, Australia. Retrieved from: https:// responsiblegambling.vic.gov.au/resources/publications/thevictorian-gambling-study-a-longitudinal-study-of-gamblingand-health-in-victoria-20082012-77/.

Binde, P. (2009). Gambling motivation and involvement: A review of social science research. Östersund, Sweden. Retrieved from: https://www.folkhalsomyndigheten.se/contentassets/ 5e4ce18338a44e38af725c7492208495/r2009-20-gamblingmotivation-a-review.pdf.

Binde, P. (2011). A Swedish mutual support society of problem gamblers. International Journal of Mental Health and Addiction, 10(4), 512-523. https://doi.org/10.1007/s11469-011-9335-4.

Binde, P. (2016). Gambling-related embezzlement in the workplace: A qualitative study. International Gambling Studies, 16(3), 391-407. https://doi.org/10.1080/14459795.2016.1214165.

Binde, P., Romild, U., \& Volberg, R. A. (2017). Forms of gambling, gambling involvement and problem gambling: Evidence from a Swedish population survey. International Gambling Studies, 17(3), 490-507. https://doi.org/10.1080/14459795.2017. 1360928.

Black, D. W., Coryell, W. H., Crowe, R. R., Shaw, M., McCormick, B., \& Allen, J. (2015). Personality disorders, impulsiveness, and novelty seeking in persons with DSM-IV pathological gambling and their first-degree relatives. Journal of Gambling Studies, 31(4), 1201-1214. https://doi.org/10.1007/s10899014-9505-y.

Blanco, C., Hanania, J., Petry, N. M., Wall, M. M., Wang, S., Jin, C. J., et al. (2015). Towards a comprehensive developmental model of pathological gambling. Addiction, 110(8), 1340-1351. https:// doi.org/10.1111/add.12946.

Blaszczynski, A., Collins, P., Fong, D., Ladouceur, R., Nower, L., Shaffer, H. J., et al. (2011). Responsible gambling: General principles and minimal requirements. Journal of Gambling Studies, 27(4), 565-573. https://doi.org/10.1007/s10899-010-9214-0.

Blaszczynski, A., Ladouceur, R., Nower, L., \& Shaffer, H. J. (2008). Informed choice and gambling: Principles for consumer protection. Journal of Gambling, Business and Economics, 2(1), 103-118.

Blaszczynski, A., Ladouceur, R., \& Shaffer, H. J. (2004). A sciencebased framework for responsible gambling: The Reno Model. Journal of Gambling Studies, 20(3), 301-317. https://doi.org/10. 1023/B:JOGS.0000040281.49444.e2. 
Bonnaire, C., Bungener, C., \& Varescon, I. (2006). Pathological gambling and sensation seeking-How do gamblers playing games of chance in cafés differ from those who bet on horses at the racetrack? Addiction Research and Theory, 14(6), 619-629. https://doi.org/10.1080/16066350600964296.

Borg, M. O., Mason, P. M., \& Shapiro, S. L. (1993). The cross effects of lottery taxes on alternative state tax revenue. Public Finance Quarterly, 21(2), 123-140. https://doi.org/10.1177/ 109114219302100201.

Borsoi, D., \& Toneatto, T. (2003). Problem-solving skills in male and female problem gamblers. Journal of Gambling Issues, 8. https://doi.org/10.4309/jgi.2003.8.14.

Boughton, R. (2002). Voices of women who gamble in Ontario: A survey of women's gambling, barriers to treatment and treatment service needs. Responsible Gambling Council. Niagara Falls, ON. Retrieved from: http://www.greo.ca/Modules/ EvidenceCentre/files/Boughton\%20\%282002\%29Voices\%20of\% 20women\%20who\%20gamble\%20in\%20Ontario.pdf.

Breen, H., \& Gainsbury, S. (2013). Aboriginal gambling and problem gambling: A review. International Journal of Mental Health and Addiction, 11(1), 75-96. https://doi.org/10.1007/ s11469-012-9400-7.

Brooks, G. A., \& Clark, L. (2019). Associations between loot box use, problematic gaming and gambling, and gambling-related cognitions. Addictive Behaviors, 96, 26-34. https://doi.org/10. 1016/j.addbeh.2019.04.009.

Browne, M., Greer, N., Rawat, V., \& Rockloff, M. (2017). A population-level metric for gambling-related harm. International Gambling Studies, 17(2), 163-175. https://doi.org/10.1080/ 14459795.2017.1304973.

Browne, M., Langham, E., Rawat, V., Greer, N., Li, E., Rose, J., et al. (2016). Assessing gambling-related harm in victoria: A public health perspective. VIC, Australia. Retrieved from: https://www. responsiblegambling.vic.gov.au/information-and-resources/ research/recent-research/assessing-gambling-related-harm-invictoria-a-public-health-perspective.

Browne, M., \& Rockloff, M. J. (2017). The dangers of conflating gambling-related harm with disordered gambling Commentary on: Prevention paradox logic and problem gambling (Delfabbro \& King, 2017). Journal of Behavioral Addictions, 6(3), 317-320. https://doi.org/10.1556/2006.6.2017.059.

Calado, F., Alexandre, J., \& Griffiths, M. D. (2017). Prevalence of adolescent problem gambling: A systematic review of recent research. Journal of Gambling Studies, 33(2), 397-424. https:// doi.org/10.1007/s10899-016-9627-5.

Calado, F., \& Griffiths, M. D. (2016). Problem gambling worldwide: An update and systematic review of empirical research (2000-2015). Journal of Behavioral Addictions, 5(4), 592-613. https://doi.org/10.1556/2006.5.2016.073.

Cassidy, R. (2014). 'A place for men to come and do their thing': Constructing masculinities in betting shops in London. British Journal of Sociology, 65(1), 170-191. https://doi.org/10.1111/ 1468-4446.12044.

Castellani, B. (2000). Pathological gambling: The making of a medical problem. Albany, NY: State University of New York Press.

Chebli, J. L., Blaszczynski, A., \& Gainsbury, S. M. (2016). Internetbased interventions for addictive behaviours: A systematic review. Journal of Gambling Studies, 32(4), 1279-1304. https:// doi.org/10.1007/s10899-016-9599-5.

Collins, P., Blaszczynski, A., Ladouceur, R., Shaffer, H. J., Fong, D., \& Venisse, J. L. (2015). Responsible gambling: Conceptual considerations. Gaming Law Review \& Economics-Regulation Compliance and Policy, 19(8), 594-599. https://doi.org/10.1089/ glre.2015.1985.

Cotti, C. (2008). The effect of casinos on local labor markets: A county level analysis. Journal of Gambling Business and Economics, 2(2), 17-41. https://doi.org/10.5750/jgbe.v2i2.529.

Currie, S. R., \& the Lower Risk Gambling Guidelines Scientific Working Group. (2018). A research plan to define Canada's first low-risk gambling guidelines. Health Promotion International, 34(6), 1207-1217. https://doi.org/10.1093/heapro/day074.

Currie, S. R., Hodgins, D. C., Casey, D. M., el-Guebaly, N., Smith, G. J., Williams, R. J., et al. (2017). Deriving low-risk gambling limits from longitudinal data collected in two independent Canadian studies. Addiction, 112(11), 2011-2020. https://doi. org/10.1111/add.13909.

d'Astous, A., \& Di Gaspero, M. (2015). Heuristic and analytic processing in online sports betting. Journal of Gambling Studies, 31(2), 455-470. https://doi.org/10.1007/s10899-013-9438-x.

Delfabbro, P., \& King, D. (2017). Prevention paradox logic and problem gambling: Does low-risk gambling impose a greater burden of harm than high-risk gambling? Journal of Behavioral Addictions, 6(2), 163-167. https://doi.org/10.1556/2006.6.2017.022.

Delfabbro, P. \& King, D.L. (2019). Challenges in the conceptualisation and measurement of gambling-related harm. Journal of Gambling Studies, 35(2), 743-755. https://doi.org/10. 1007/s10899-019-09844-1.

Derevensky, J. L., St-Pierre, R. A., Temcheff, C. E., \& Gupta, R. (2014). Teacher awareness and attitudes regarding adolescent risky behaviours: Is adolescent gambling perceived to be a problem? Journal of Gambling Studies, 30(2), 435-451. https:// doi.org/10.1007/s10899-013-9363-z.

Dickler, M., Lenglos, C., Renauld, E., Ferland, F., Edden, R. A., Leblond, J., et al. (2018). Online effects of transcranial direct current stimulation on prefrontal metabolites in gambling disorder. Neuropharmacology, 131, 51-57. https://doi.org/10. 1016/j.neuropharm.2017.12.002.

Dixon, M. J., Harrigan, K. A., Sandhu, R., Collins, K., \& Fugelsang, J. A. (2010). Losses disguised as wins in modern multi-line video slot machines. Addiction, 105(10), 1819-1824. https://doi. org/10.1111/j.1360-0443.2010.03050.x.

Dow Schull, N. (2002). Escape mechanism: Women, caretaking, and compulsive machine gambling. Working Paper No. 41. Berkeley, CA: University of California, Berkeley.

Dowling, N. A., Cowlishaw, S., Jackson, A. C., Merkouris, S. S., Francis, K. L., \& Christensen, D. R. (2015). Prevalence of psychiatric co-morbidity in treatment-seeking problem gamblers: A systematic review and meta-analysis. Australian and New Zealand Journal of Psychiatry, 49(6), 519-539. https://doi.org/ 10.1177/0004867415575774.

Dowling, N. A., Merkouris, S. S., Greenwood, C. J., Oldenhof, E., Toumbourou, J. W., \& Youssef, G. J. (2017). Early risk and protective factors for problem gambling: A systematic review and meta-analysis of longitudinal studies. Clinical Psychology Review, 51, 109-124. https://doi.org/10.1016/j.cpr.2016.10.008. 
Dowling, N., Suomi, A., Jackson, A., Lavis, T., Patford, J., Cockman, S., et al. (2016b). Problem gambling and intimate partner violence: A systematic review and meta-analysis. Trauma, Violence, \& Abuse, 17(1), 43-61. https://doi.org/10.1177/1524838014561269.

Dowling, N. A., Youssef, G. J., Jackson, A. C., Pennay, D. W., Francis, K. L., Pennay, A., et al. (2016a). National estimates of Australian gambling prevalence: Findings from a dual-frame omnibus survey. Addiction, 111(3), 420-435. https://doi.org/10. 1111/add.13176.

Drummond, A., \& Sauer, J. D. (2018). Video game loot boxes are psychologically akin to gambling. Nature Human Behaviour, 2(8), 530-532. https://doi.org/10.1038/s41562-018-0360-1.

Eber, G. B., \& Shaffer, H. J. (2000). Trends in bio-behavioral gambling studies research: Quantifying citations. Journal of Gambling Studies, 16(4), 461-467. https://doi.org/10.1023/A: 1009440425186.

el-Guebaly, N., Casey, D. M., Currie, S. R., Hodgins, D. C., Schopflocher, D. P., Smith, G. J., et al. (2015). The leisure, Lifestyle, \& lifecycle Project (LLLP): A longitudinal study of gambling in Alberta. Final report. Calgary, AB. Retrieved from: https://prism.ucalgary.ca/handle/1880/50377.

Ferentzy, P., Skinner, W., \& Antze, P. (2010). The serenity prayer: Secularism and spirituality in Gamblers Anonymous. Journal of Groups in Addiction \& Recovery, 5(2), 124-144. https://doi.org/ 10.1080/15560351003766125.

Forrest, D., \& Wardle, H. (2011). Gambling in Asian communities in Great Britain. Asian Journal of Gambling Issues and Public Health, 2(1), 2-16. https://doi.org/10.1186/BF03342121.

Fox, K. (2005). The racing tribe: Watching the horsewatchers. London, UK: Metro Publishing.

Gainsbury, S. M., King, D. L., Abarbanel, B., Delfabbro, P., \& Hing, N. (2015a). Convergence of gambling and gaming in digital media. Melbourne, Australia. Retrieved from: https://www. responsiblegambling.vic.gov.au/_data/assets/pdf_file/0003/25572/ Gainsbury_convergence_of_gambling_and_gaming_2015.pdf.

Gainsbury, S., King, D., Delfabbro, P., Hing, N., Russell, A., Blaszczynski, A., et al. (2015b). The use of social media in gambling. Melbourne, Australia. Retrieved from: https://www. responsiblegambling.nsw.gov.au/_data/assets/pdf_file/0004/ 138127/The-use-of-social-media-in-gambling.pdf.

Genauck, A., Quester, S., Wüstenberg, T., Mörsen, C., Heinz, A., \& Romanczuk-Seiferth, N. (2017). Reduced loss aversion in pathological gambling and alcohol dependence is associated with differential alterations in amygdala and prefrontal functioning. Scientific Reports, 7(1), 16306. https://doi.org/10.1038/ s41598-017-16433-y.

Gooding, P., \& Tarrier, N. (2009). A systematic review and metaanalysis of cognitive-behavioural interventions to reduce problem gambling: Hedging our bets? Behaviour Research and Therapy, 47(7), 592-607. https://doi.org/10.1016/j.brat.2009.04.002.

GREO. (2018). Interactive conceptual framework of harmful gambling. Retrieved from https://www.greo.ca/en/frameworks/ conceptual-framework.aspx.

Goodman, R. (1994). Legalized gambling as a strategy for economic development. Amherst, MA: United States Gambling Study. Retrieved from https://prism.ucalgary.ca/handle/1880/47995.

Grinols, E. (2004). Gambling in America: costs and benefits. New York: Cambridge University Press.
Grinols, E. L., \& Omorov, J. D. (1996). Development or dreamfield delusions: Assessing casino gambling's costs and benefits. Journal of Law and Commerce, 16, 49-87.

Griswold, M. T., \& Nichols, M. W. (2006). Social capital and casino gambling in U.S. communities. Social Indicators Research, 77(3), 369-394. https://doi.org/10.1007/s11205-0046337-7.

Grote K. R., \& Matheson, V. A. (2013). The impact of state lotteries and casinos on state bankruptcy filings. Growth and Change, 45(1), 121-135. https://doi.org/10.1111/grow.12030.

Hancock, L., \& Smith, G. (2017). Critiquing the Reno Model I-IV international influence on regulators and governments (2004-2015) - the distorted reality of "responsible gambling". International Journal of Mental Health and Addiction, 15(6), 1151-1176. https://doi.org/10.1007/s11469-017-9746-y.

Hartmann, M., \& Blaszczynski, A. (2018). The longitudinal relationships between psychiatric disorders and gambling disorders. International Journal of Mental Health and Addiction, 16, 16-44. https://doi.org/10.1007/s11469-016-9705-z.

Hilbrecht, M., \& Mock, S. E. (2019). Low-risk, moderate-risk, and recreational gambling among older adults: Self-complexity as a buffer for quality of life. Applied Research in Quality of Life, 14(5), 1205-1227. https://doi.org/10.1007/s11482-0189648-6.

Holdsworth, L., \& Tiyce, M. (2013). Untangling the complex needs of people experiencing gambling problems and homelessness. International Journal of Mental Health and Addiction, 11(2), 186-198. https://doi.org/10.1007/s11469-012-9409-y.

Horch, J. D., \& Hodgins, D. (2008). Public stigma of disordered gambling: Social distance, dangerousness, and familiarity. Journal of Social and Clinical Psychology, 27(5), 505-528. https://doi.org/10.1521/jscp.2008.27.5.505.

Horch, J., \& Hodgins, D. (2013). Stereotypes of problem gambling. Journal of Gambling Issues, 28, 19. https://doi.org/10.4309/jgi. 2013.28.10.

Humphreys, B. R., \& Marchand, J. (2013). New casinos and local labor markets: Evidence from Canada. Labour Economics, 24, 151-160. https://doi.org/10.1016/j.labeco.2013.08.006.

Hunt, C. J., \& Gonsalkorale, K. (2018). Conformity to masculine norms among treatment-seeking male problem gamblers. International Gambling Studies, 18(3), 408-419. https://doi.org/ 10.1080/14459795.2018.1429482.

Jacoby, N., von Lersner, U., Schubert, H. J., Loeffler, G., Heinz, A., \& Mörsen, C. P. (2013). The role of acculturative stress and cultural backgrounds in migrants with pathological gambling. International Gambling Studies, 13(2), 240-254. https://doi.org/ 10.1080/14459795.2013.777971.

Johnson, M. R. (2018). The unpredictability of gameplay. New York, NY: Bloomsbury Academic.

Kairouz, S., Nadeau, L., \& Robillard, C. (2014). Portrait du jeu au Québec: Prévalence, incidence et trajectoires sur quatre ans. Montreal, QC. Retrieved from: https://www.concordia.ca/ content/dam/artsci/research/lifestyle-addiction/docs/projects/ enhjeu-q/ENHJEU-QC-2012_rapport-final-FRQ-SC.pdf.

Keatley, D., Parke, A., Townsend, E., Markham, C., \& Clarke, D. (2019). A behaviour sequence analysis of young people and gambling-related harm. Journal of Gambling Issues, 43, $1-19$. 
Kim, W. (2012). Acculturation and gambling in Asian Americans: When culture meets availability. International Gambling Studies, 12(1), 69-88. https://doi.org/10.1080/14459795.2011. 616908.

Korn, D. A., \& Shaffer, H. J. (1999). Gambling and the health of the public: Adopting a public health perspective. Journal of Gambling Studies, 15(4), 289-365.

Kovacs, I., Richman, M. J., Janka, Z., Maraz, A., \& Ando, B. (2017). Decision making measured by the Iowa gambling task in alcohol use disorder and gambling disorder: A systematic review and meta-analysis. Drug and Alcohol Dependence, 181, 152-161. https://doi.org/10.1016/ j.drugalcdep.2017.09.023.

Krauss, F. (2010). Taking the points: The socialization process of a sports book "regular". Center for Gambling Research, University of Nevada. Las Vegas, NV. Retrieved from: http://gaming.unlv. edu/papers/cgr_op07_krauss.pdf.

Ladouceur, R., Ferland, F., Côté, M.A., \& Vitaro, F. (2004). Teachers' knowledge and training needs regarding youth gambling. School Psychology International, 25(4), 472-479. https://doi.org/10.1177/0143034304048780.

LaPlante, D. A., Gray, H. M., Williams, P. M., \& Nelson, S. E. (2018). An empirical review of gambling expansion and gambling-related harm. Sucht, 64(5-6), 295-306. https://doi. org/10.1024/0939-5911/a000563.

Ligneul, R., Sescousse, G., Barbalat, G., Domenech, P., \& Dreher, J. C. (2013). Shifted risk preferences in pathological gambling. Psychological Medicine, 43(5), 1059-1068. https://doi.org/10. 1017/s0033291712001900.

Limbrick-Oldfield, E. H., van Holst, R. J., \& Clark, L. (2013). Fronto-striatal dysregulation in drug addiction and pathological gambling: Consistent inconsistencies? NeuroImage: Clinical, 2(1), 385-393. https://doi.org/10.1016/j.nicl.2013.02.005.

Livingstone, C. (2001). The social economy of poker machine gambling in Victoria. International Gambling Studies, 1(1), 46-65. https://doi.org/10.1080/14459800108732287.

Lussier, I. D., Derevensky, J., Gupta, R., \& Vitaro, F. (2014). Risk, compensatory, protective, and vulnerability factors related to youth gambling problems. Psychology of Addictive Behaviors, 28(2), 404-413. https://doi.org/10.1037/a0034259.

Manitowabi, D. (2011). Casino Rama: First Nations self-determination, neoliberal solution or partial middle ground? In Y. D. Belanger (Ed.), First nations gaming in Canada (pp. 255-278). Winnipeg, MB: University of Manitoba Press.

Mason, E. (2017). An ecological and life course analysis of binge drinking and problem gambling among Indigenous populations in Canada (Masters Thesis). Lethbridge, AB: University of Lethbridge.

Matheson, F. I., Devotta, K., Wendaferew, A., \& Pedersen, C. (2014). Prevalence of gambling problems among the clients of a Toronto homeless shelter. Journal of Gambling Studies, 30(2), 537-546. https://doi.org/10.1007/s10899-014-9452-7.

Mazar, A., Volberg, R. A., Williams, R. J., Stanek , III, E. J., \& Zorn, M. (2019). The MA gambling impact cohort: Analyses across three waves. Amherst, MA: School of Public Health and Health Sciences, University of Massachusetts. Retrieved from: https:// www.umass.edu/seigma/sites/default/files/MAGIC\%20Wave\% 203\%20Report_Final_2019-09-12.pdf.
Merkouris, S. S., Thomas, S. A., Browning, C. J., \& Dowling, N. A. (2016). Predictors of outcomes of psychological treatments for disordered gambling: A systematic review. Clinical Psychology Review, 48, 7-31. https://doi.org/10.1016/j.cpr.2016.06.004.

Moellman, N., \& Mitra, A. (2013). Indian gaming in Oklahoma: Implications for community welfare. The Journal of SocioEconomics, 45, 64-70.

Molinaro, S., Benedetti, E., Scalese, M., Bastiani, L., Fortunato, L., Cerrai, S., et al. (2018). Prevalence of youth gambling and potential influence of substance use and other risk factors throughout 33 European countries: First results from the 2015 ESPAD study. Addiction, 113(10), 1862-1873. https://doi.org/10. 1111/add.14275.

Nower, L., \& Caler, K. R. (2018). Widening the net: A syndemic approach to responsible gambling. Sucht, 64, 317-323. https:// doi.org/10.1024/0939-5911/a000565.

Ocean, G., \& Smith, G. J. (1993). Social reward, conflict, and commitment: A theoretical model of gambling behavior. Journal of Gambling Studies, 9(4), 321-339. https://doi.org/10.1007/ BF01014625.

Pearce, J., Mason, K., Hiscock, R., \& Day, P. (2008). A national study of neighbourhood access to gambling opportunities and individual gambling behaviour. Journal of Epidemiology \& Community Health, 62(10), 862-868. https://doi.org/10.1136/ jech.2007.068114.

Poole, J. C., Kim, H. S., Dobson, K. S., \& Hodgins, D. C. (2017). Adverse childhood experiences and disordered gambling: Assessing the mediating role of emotion dysregulation. Journal of Gambling Studies, 33(4), 1187-1200. https://doi.org/10.1007/ s10899-017-9680-8.

Puri, S. S. (2014). Speculation in fixed futures: An ethnography of betting in between legal and illegal economies at the Delhi racecourse. (Unpublished doctoral dissertation). University of Copenhagen, Copenhagen, Denmark.

Quilty, L. C., Wardell, J. D., Thiruchselvam, T., Keough, M. T., \& Hendershot, C. S. (2019). Brief interventions for problem gambling: A meta-analysis. PloS One, 14(4), e0214502. https:// doi.org/10.1371/journal.pone.0214502.

Quinlan, C. K., Goldstein, A. L., \& Stewart, S. H. (2014). An investigation of the link between gambling motives and social context of gambling in young adults. International Gambling Studies, 14(1), 115-131. https://doi.org/10.1080/14459795.2013. 855252.

Rawat, V., Browne, M., Bellringer, M., Greer, N., KolandaiMatchett, K., Rockloff, M., et al. (2018). A tale of two countries: Comparing disability weights for gambling problems in New Zealand and Australia. Quality of Life Research: An International Journal of Quality of Life Aspects of Treatment, Care and Rehabilitation, 27(9), 2361-2371. https://doi.org/10.1007/ s11136-018-1882-8.

Reith, G., \& Dobbie, F. (2013). Gambling careers: A longitudinal, qualitative study of gambling behaviour. Addiction Research and Theory, 21(5), 376-390. https://doi.org/10.3109/16066359. 2012.731116.

Rintoul, A. C., Livingstone, C., Mellor, A. P., \& Jolley, D. (2012). Modelling vulnerability to gambling related harm: How disadvantage predicts gambling losses. Addiction Research and Theory, 21(4), 329-338. https://doi.org/10.3109/16066359.2012.727507. 
Romild, U., Svensson, J., \& Volberg, R. (2017). A gender perspective on gambling clusters in Sweden using longitudinal data. Nordic Studies on Alcohol and Drugs, 33(1), 43-60. https://doi. org/10.1515/nsad-2016-0004.

Romild, U., Volberg, R., \& Abbott, M. (2014). The Swedish longitudinal gambling study (swelogs): Design and methods of the epidemiological (EP-) track. International Journal of Methods in Psychiatric Research, 23(3), 372-386. https://doi.org/10.1002/ mpr.1449.

Rosecrance, J. (1985). Compulsive gambling and the medicalization of deviance. Social Problems, 32(3), 275-284. https://doi.org/10. $2307 / 800687$.

Rosecrance, J. (1986). Why regular gamblers don't quit. Sociological Perspectives, 29(3), 357-378. https://doi.org/10.2307/1389025.

Saugeres, L., Thomas, A., \& Moore, S. (2014). 'It wasn't a very encouraging environment': Influence of early family experiences on problem and at-risk gamblers in Victoria, Australia. International Gambling Studies, 14(1), 132-145. https://doi.org/ 10.1080/14459795.2013.879729.

Savage, J. E., Slutske, W. S., \& Martin, N. G. (2014). Personality and gambling involvement: A person-centered approach. Psychology of Addictive Behaviors, 28(4), 1198-1211. https://doi.org/10. 1037/a0037413.

Shaffer, H. J., Stanton, M. V., \& Nelson, S. E. (2006). Trends in gambling studies research: Quantifying, categorizing, and describing citations. Journal of Gambling Studies, 22(4), 427-442. https://doi.org/10.1007/s10899-006-9023-7.

Sharman, S., Dreyer, J., Clark, L., \& Bowden-Jones, H. (2016). Down and out in London: Addictive behaviors in homelessness. Journal of Behavioral Addictions, 5(2), 318-324. https://doi.org/ 10.1556/2006.5.2016.037.

Slutske, W. S., Zhu, G., Meier, M. H., \& Martin, N. G. (2010). Genetic and environmental influences on disordered gambling in men and women. Archives of General Psychiatry, 67(6), 624630. https://doi.org/10.1001/archgenpsychiatry.2010.51.

Straus, S. E., Tetroe, J., \& Graham, I. (2009). Defining knowledge translation. Canadian Medical Association Journal = journal de l'Association medicale canadienne, 181(3-4), 165-168. https:// doi.org/10.1503/cmaj.081229.

Substance Abuse and Mental Health Services Association. (2010). Risk and protective factors for mental, emotional, and behavioral disorders across the life cycle. Anchorage, AK. Retrieved from: http://dhss.alaska.gov/dbh/Documents/Prevention/programs/ spfsig/pdfs/IOM_Matrix_8\%205x11_FINAL.pdf.

Tabri, N., Wohl, M. J. A., Eddy, K. T., \& Thomas, J. J. (2016). Me, myself and money: Having a financially focused self-concept and its consequences for disordered gambling. International Gambling Studies, 17(1), 30-50. https://doi.org/10.1080/ 14459795.2016.1252414.

Tang, C. S.k., \& Oei, T. P. (2011). Gambling cognition and subjective well-being as mediators between perceived stress and problem gambling: A cross-cultural study on white and Chinese problem gamblers. Psychology of Addictive Behaviors, 25(3), 511-520.

Taylor, L. F., Macaskill, A. C., \& Hunt, M. J. (2017). Realistic freespins features increase preference for slot machines. Journal of Gambling Studies, 33(2), 555-577. https://doi.org/10.1007/ s10899-016-9630-x.
Thompson, W. N., Gazel, R., \& Rickman, D. (1997). Social and legal costs of compulsive gambling. Gaming Law Review, 1(1), 81-89. https://doi.org/10.1089/glr.1997.1.81.

Toneatto, T., \& Nguyen, L. (2007). Individual characteristics and problem gambling behaviour. In G. Smith, D. C. Hodgins, \& R. Williams (Eds.), Research and measurement issues in gambling studies (pp. 279-303). New York, NY: Elsevier.

van der Maas, M., Shi, J., Elton-Marshall, T., Hodgins, D. C., Sanchez, S., Lobo, D. S., et al. (2019). Internet-based interventions for problem gambling: Scoping review. JMIR Mental Health, 6(1), e65. https://doi.org/10.2196/mental.9419.

Walker, D. M. (2003). Methodological issues in the social cost of gambling studies. Journal of Gambling Studies, 19(2), 149-184. https://doi.org/10.1023/A:1023629331837.

Walker, D. M. (2010). Casinos and crime in the U.S.A. In Handbook on the economics of crime (pp. 488-517). Cheltenham, UK: Edward Elgar Publishing.

Walker, D. M., \& Barnett, A. H. (1999). The social costs of gambling: An economic perspective. Journal of Gambling Studies, 15(3), 181-212. https://doi.org/10.1023/A:1023089111024.

Walker, D. M., \& Jackson, J. D. (2011). The effect of legalized gambling on state government revenue. Contemporary Economic Policy, 29(1), 101-114. https://doi.org/10.1111/j.14657287.2010.00198.x.

Wardle, H., Reith, G., Langham, E., \& Rogers, R. D. (2019). Gambling and public health: we need policy action to prevent harm. BMJ, 365, 1807. https://doi.org/10.1136/bmj.11807.

Williams, R. J., Hann, R., Schopflocher, D., West, B., McLaughlin, P., White, N., et al. (2015). Quinte longitudinal study of gambling and problem gambling: Report prepared for the Ontario problem gambling research Centre. Guelph, ON, Canada. Retrieved from: http://www.greo.ca/Modules/ EvidenceCentre/files/Williams\%20et\%20al\%20\%282015\% 29Quinte_longitudinal_study_of_gambling_and_PG.pdf.

Williams, R. J., Rehm, J., \& Stevens, R. M. G. (2011a). The social and economic impacts of gambling. Calgary, $\mathrm{AB}$. Retrieved from: https:/www.uleth.ca/dspace/bitstream/handle/10133/1286/ SEIG_FINAL_REPORT_2011.pdf.

Williams, R. J., Royston, J., \& Hagen, B. F. (2005). Gambling and problem gambling within forensic populations: A review of the literature. Criminal Justice and Behavior, 32(6), 665-689. https://doi.org/10.1177/0093854805279947.

Williams, R. J., Stevens, R. M. G., \& Nixon, G. (2011b). Gambling and problem gambling in North American Aboriginal peoples. In Y. D. Belanger (Ed.), First nations gaming in Canada (pp. 166-194). Winnipeg, MB: University of Manitoba Press.

Williams, R. J. \& Volberg, R. A. (2013). Gambling and problem gambling in Ontario. Report prepared for the Ontario Problem Gambling Research Centre and the Ontario Ministry of Health and Long Term Care. June 17, 2013. http://hdl.handle.net/ $10133 / 3378$.

Williams, R. J., Volberg, R., \& Stevens, R. M. G. (2012). The population prevalence of problem gambling: Methodological influences, standardized rates, jurisdictional differences, and worldwide trends. Guelph, ON. Retrieved from: http://www.greo.ca/Modules/ EvidenceCentre/Details/population-prevalence-problem-gamblingmethodological-influences-standardized-rates- 0 . 
Wohl, M. J. A., Kim, H. S., Salmon, M., Santesso, D., Wildschut, T., \& Sedikides, C. (2018). Discontinuity-induced nostalgia improves the odds of a self-reported quit attempt among people living with addiction. Journal of Experimental Social Psychology, 75, 83-94. https://doi.org/10.1016/j.jesp.2017.11.011.

World Health Organization. (2018). Global status report on alcohol and health 2018. Geneva. Retrieved from: http://apps.who.int/ iris/bitstream/handle/10665/274603/9789241565639-eng.pdf? $\mathrm{ua}=1 \& \mathrm{ua}=1$.
Yip, S. W., \& Potenza, M. N. (2014). Treatment of gambling disorders. Current Treatment Options in Psychiatry, 1(2), 189-203. https://doi.org/10.1007/s40501-014-0014-5.

Zack, M., Cho, S. S., Parlee, J., Jacobs, M., Li, C., Boileau, I., et al. (2016). Effects of high frequency repeated transcranial magnetic stimulation and continuous theta burst stimulation on gambling reinforcement, delay discounting, and Stroop interference in men with pathological gambling. Brain Stimulation, 9(6), 867-875. https://doi.org/10.1016/j.brs.2016.06.003. 